SURYABALA

Translated by Puja Birla

\title{
The Tradition of Prizes in Hindi Literature
}

Born in 1944, Suryabala published her first short story at the age of seventeen. Well-known to Hindi readers, she has written several novels and volumes of short stories. Suryabala's Dhritrashtra Times is a collection of nonfiction satire, dangerously veering towards spoof, that first appeared in 2001. Dhritrashtra is the blind-literally and metaphorically-king from the epic, Mahabharata, who can't actually take part in the climactic battle. He gets a blow-by-blow account of the fighting from his charioteer, Sanjaya. But should Dhritrashtra trust this ancient freelance reporter? Suryabala's satirical eye turns to politics, media, society, and herself to report a more complex reality. It treats, with crafty irreverence, venerable figures and traditions of mythology, literature, and popular culture. In all she has written four volumes of satire, the most recent appearing in February 2008.

The reader of literature in the Indian languages, including Hindi, repeatedly encounters an oral, performative quality in the written works. Several of Suryabala's pieces in this collection give the reader a sense of a single actor playing all the different roles. Although the narrative shifts sound unusual-some may say jarring - in English, as a translator, I am interested in the limits to which I can bend the language to retell a story in it, while at the same time indicating to my reader that it wasn't told in English first.

Writers of Hindi literature can be divided into two major groupsprized and unprized. Broadly speaking, prized writers are those who use swear words in their work and unprized are those who use them in their speech. This is a rich and effective tradition. The type of swear words and the frequency with which they are used depends on the prized writer's profound insights, life philosophy, interests, and personal perspective, along with the stipulations of the award committee. Some prizes are confined to literature rife with foul language in the same way that some films are rated $\mathrm{R}$.

Forgive me, a minor correction. Unprized writers also come in two varieties. The first are those who, upon witnessing others lunge at awards, despairingly think-O Lord! This wretched soul doesn't realize the type of danger he is undertaking for the sake of his art. 
The second group comprises those who despairingly think-Oh how I wish I was in this danger!

Although, as far as despondency goes, prized writers experience it too, in fact, more than the unprized ones. While the latter is depressed only because he hasn't got the award, the prized writer is incessantly inconsolable since said prize has been given to him after such a prolonged period. Couldn't he have got it four, six, even eight years back? And fine, he has got it but why do others have to get it too? Also, would it have been terribly inconvenient if he had been given the prizes that they already got? And finally, why are those prizes more prestigious than the one he has just won? Conclusion: the source of sorrow for unprized writers is one-for prized, a hundred and one.

Certainly, there is one similarity between both groups-according to each and every writer, prized or unprized, besides their own work, the rest of so-called contemporary literature is apathetic, badly-conceived, unstable, fit only for rejection.

Anyway, these are but high-level, theoretical, and ideological issues. Let's leave them and look at the legendary battleground of Jhansi where both armies, the prized and the unprized, have pitched camps. Both are palpably eager. What's that? Such-and-such prize has been announced for so-and-so? And our trust-trustees, sponsors-sponsorship, our academies, who postponed bestowing this honor, have been caught sleeping! Who cares about the writer! How is it that this award managed to get there first and gain more headlines than ours?

Never mind, we'll also give our prize. Make the announcement, and listen, increase the cash amount so our prize carries Rupees 25 more than the other one. Make sure we get all the headlines, our media coverage shouldn't be any less than what the other one attracted. We don't hand out a prize to illustrate the eminence or greatness of the writer but to emphasize the superiority of the prize. If the writer is considered outstanding, it is not because he writes well but because he has received a prize. The moment the generous shade of an influential grant envelopes a writer, there is a noticeable excitement all around in various camps. Sweetly sleeping newspapers and magazines, writers and reviewers, radio and TV announcers, all abandon their cozy bedsides and warm armchairs to rush in that direction; close behind them and adding to the queue 
are publishers and other miscellaneous rabble, carrying the ubiquitous shawl and prasad. The hapless writer must be thinking as he looks from the long lines of felicitating visitors to the endless yards of shawl and mounds of prasad plates-Kindred spirits, where have you been all this time?

Meanwhile, as the prize parade passes, the dust rises in the camp of the unprized. How long can one be patient? Dusting themselves off, the compadres prepare to take action. Instead of accepting any old prize in the heat of the moment, they make plans to bestow some of their own. Every writer announces a prize in the name of his father, son, and wife (the last only if she is deceased), and immediately allots it to a friend. The prized friend repeats the action letter-for-letter, thus saving the first friend from the ignominy of nonrecognition. Making continuous headway, this reciprocal gesture is dedicated to the service of turning a large portion of the writing population into prized artists. It has been estimated that in the next few years, poverty and hunger may or may not be eradicated from India but the category of unprized writers will be wiped out forever. The whole world will yearn to lay eyes on at least one Indian writer who remains unprized.

Presently though, the situation is different. Often the unprized ones come to me and ask, in their own way, how to free themselves from the suffering and sorrow of not receiving a prize. As a way out, I usually suggest that they don't send their books to the awarding trust or foundation. Under such circumstances, one has absolute liberty to say to oneself and others-I didn't even send my book, how am I supposed to get the prize!

That's when these emerging stars tell me that if they don't send their books, some foundations send extremely demanding letters, which finally turn threatening. The intention and tone is somewhat like this: Please note, this is your third notification letter. We have informed you prior to this that as per the proviso of our prize, we have collected unwavering support for the firm decision to honor you. Therefore, on receipt of this notification, please send four copies of each of your books to us post haste, and if that's not possible, send whatever you have. If your writing has not been published yet, please send a story to the competition organized by our sister magazine. Anything will do. We want to assure you that among the several prizes, ranging from a cash award of Rupees 5 to Rupees 50, 
you are certain to win at least one. Please act immediately. Kindly note-the nonpartcipating writer who does not send his books and does not participate in the awards will be subject to deadly repercussions.

Subdued and frightened, the writer actually sits down to write a story full of pathos for said competition when the postman delivers some 'personal' and 'confidential' letters. According to these, the writer is warned that he may face deadly repercussions if he doesn't participate in the above mentioned contests. Caught between the fatal kismet of two literary constants, the poor writer begins looking for Salman Rushdie's basement or Saddam Hussein's bunker. This prized tradition is what makes contemporary literature wail tears of terror.

So, the moral of the story: The prize-giving custom has a distinct place of significance in the propitious growth of Hindi literature. It has encouraged a reciprocal solidarity between writers, editors, and journalists-you accept the prize bearing my name and give me the one bearing yours. By thus taking and giving prizes we help each other flourish, whether literature flourishes or not. 